\title{
MODERN INSTRUMENTAL METHODS FOR QUALITATIVE AND QUANTITATIVE ANALYSIS OF LAPATINIB IN BIOLOGICAL FLUIDS AND DOSAGE FORMS (REVIEW)
}

\author{
ZOYA S. SHPRAKH ${ }^{1,2}$, YANA A. POSKEDOVA ${ }^{2}$, GALINA V. RAMENSKAYA ${ }^{2}$
}

${ }^{1}$ N. N. Blokhin National Medical Research Center of Oncology (N. N. Blokhin NMRCO), 24 Kashirskoye sh., Moscow, 115478, Russia, ${ }^{2}$. M. Sechenov First Moscow State Medical University (Sechenov University), 8-2 Trubetskaya st., Moscow, 119991, Russia

*Email: yana.poskedova@outlook.com

Received: 28 Aug 2021, Revised and Accepted: 12 Nov 2021

\section{ABSTRACT}

Lapatinib is a small molecule, a heterocyclic quinazoline derivative. The drug is used for targeted therapy of patients with breast cancer, in which there is overexpression of the human epidermal growth factor receptors (HER/ErbB). This review is devoted to studying modern instrumental methods of qualitative and quantitative analysis of lapatinib, which can be used both for quality control and standardization (of bulk pharmaceuticals and dosage forms) and pharmacokinetics studies of a drug. Reverse-phase high-performance liquid chromatography (RP-HPLC) is mainly used to identify lapatinib in tablets. Depending on the purpose of the study, various detectors are used (ultraviolet or diode-matrix detector), which makes it possible to determine not only the native compound but also the products of its degradation. Definition of lapatinib in the presence of degraded products is necessary for forced degradation studies to determine drug stability. When a drug is being developed, it is important to define and understand its pharmacokinetics. For such studies, high-performance liquid chromatography (HPLC) coupled with the mass selective detector is often used. It allows determining lapatinib in biological fluids. However, these methods are not applicable for identifying the drug directly in dosage forms and require further development and validation.

Keywords: Lapatinib, HPLC, Fluorimetry, Validation, Simultaneous determination, Pharmacokinetics

(C) 2022 The Authors. Published by Innovare Academic Sciences Pvt Ltd. This is an open access article under the CC BY license (https://creativecommons.org/licenses/by/4.0/) DOI: https://dx.doi.org/10.22159/ijap.2022v14i1.42992. Journal homepage: https://innovareacademics.in/journals/index.php/ijap

\section{INTRODUCTION}

Breast cancer is the most common malignant tumor in women in the world [1]. Overexpression or activation of the HER/ErbB is often observed in breast cancer. Moreover, in 15-20 percent of cases, overexpression of human epidermal growth factor receptor 2 (HER2/neu) is observed [2]. One of the treatment options for such patients is the use of targeted therapy, which is aimed at disrupting specific biological processes that lead to tumor growth [3]. The main strategies of targeted therapy are, on the one hand, the use of monoclonal antibodies (for example, trastuzumab, pertuzumab, etc.), and on the other, tyrosine kinase inhibitors (TKI) (for example, lapatinib, neratinib, etc.) [4].

The advantages of using TKI are the oral administration, a variety of targets, and less cardiotoxicity compared to monoclonal antibodies administered intravenously (i. v.) [5]. Moreover, the use of TKI (in particular, lapatinib) has made it possible to overcome resistance to trastuzumab [6].

Lapatinib (N-[3-Chloro-4-(3-fluorobenzyloxy) phenyl]-6-[5-[[[2(methylsulfonyl)ethyl] amino] methyl]-2-furyl] quinazolin-4-amine) (fig. 1) is a small molecule, a heterocyclic compound derived from quinazoline. The lapatinib molecule exists in 3 forms: monohydrate, anhydrate, and solvate crystal forms. The active substance is in the form of the monohydrate (fig. 2) and exists as a single polymorphic form [7]. The drug's mechanism of action is as follows: it disrupts the phosphorylation of epidermal growth factor receptor (HER1) and HER2/neu by reversible competitive inhibition of adenosine triphosphate (ATP) binding sites in the intracellular kinase region. This leads to disruption of downstream signalling through RAF kinases, protein kinase B (Akt), extracellular signal-regulated kinase (ERK kinase), and phospholipase $\mathrm{C}-\gamma$. As a result, the efficiency of inducing apoptosis significantly increases, which limits the development and migration of tumor cells $[8,9]$.

The drug is freely soluble in dimethyl sulfoxide (DMSO), slightly soluble in methanol, practically insoluble in acetone, alcohol, dichloromethane, and water. Due to its low solubility in water, lapatinib belongs to the II class according to the biopharmaceutical classification system (BCS) [10]. Furthermore, analysis of the thermodynamic properties of the drug indicates that the dissolution process is endothermic [11].<smiles>CS(=O)(=O)CCNCc1ccc(-c2ccc3ncnc(Nc4ccc(OCc5cccc(F)c5)c(Cl)c4)c3c2)o1</smiles>

Fig. 1: Lapatinib<smiles>[CH]c1ccc(S(=O)(=O)O)cc1</smiles>

Fig. 2: Lapatinib ditosylate monohydrate

The value of the dissociation constant $(\mathrm{pKa})$ (for the first stage pKa1 = 3.80 ; for the second stage $\mathrm{pKa} 2=7.20$ ) indicates that lapatinib is a strong base [12]. It is an extremely lipophilic molecule (distribution coefficient $(\log$ ) 5.4). It permeates membranes by passive diffusion. Due to the ability of lapatinib to cross the blood-brain barrier, the drug can be used to treat breast cancer with brain metastases [5, 13, 14]. Summarized data on the physicochemical characteristics of the drug is given in table 1. 
Table 1: Physicochemical characteristics of lapatinib

\begin{tabular}{lll}
\hline Characteristic & Value & Reference \\
\hline Appearance & Non-hygroscopic yellow crystalline solid \\
Solubility & Freely soluble in dimethyl sulfoxide (DMSO); slightly soluble in methanol; practically insoluble in & [7] \\
& acetone, alcohol, dichloromethane, water & [10] \\
Acid-base properties & Strong base (for the first stage of dissociation pKa1 = 3.80; for the second stage pKa2=7.20) \\
Lipophilicity & Extremely lipophilic (logP =5.4) \\
Isomers & None & [12] \\
\hline
\end{tabular}

One of the major disadvantages of lapatinib is limited oral bioavailability, which varies significantly from patient to patient. The main reason for the low bioavailability is its poor solubility, which necessitates very high doses of lapatinib and limits the creation of injectable forms of the drug. In addition, the clinical use of lapatinib in the form of film-coated tablets is limited by its high affinity for albumin (protein binding $>99 \%$ ), which leads to a decrease in its therapeutic effect $[15,16]$.

The scientific literature describes methods for the quantitative determination of lapatinib in conjunction with other TKI (e. g., imatinib, nilotinib, sorafenib, erlotinib, dasatinib, etc.). Such studies are used for routine analysis of these drugs in biological fluids (blood plasma, urine) during clinical trials due to the large individual variability of the pharmacokinetics of TKI [17-19]. On the other hand, lapatinib is often used in combination therapy of tumors, for example, together with monoclonal antibodies (trastuzumab), cytostatics (paclitaxel, cisplatin, temozolomide), antineoplastic hormonal agents (letrozole), and antimetabolic drugs (capecitabine) [20-25].

To prepare this review search criterion was the modern instrumental methods of qualitative and quantitative analysis of lapatinib. Literature survey has been done in a range of years 19902020 to make the review updated and comprehensive and to show the methods which can be used both for quality control and standardization (of the substance and dosage forms) and for pharmacokinetics studies of the drug. The sources were worldrecognized journals. The keywords used were "Lapatinib", "HPLC", "validation", "pharmacokinetics".

\section{Standardization of lapatinib in the dosage form}

For the determination of lapatinib in tablets, a simple, selective, fast, accurate, and cost-effective method of reverse-phase highperformance liquid chromatography coupled with an ultraviolet detector (RP-HPLC-UV) using an internal standard (IS) has been developed [26]. Methods that use an IS are most suitable for quality control of drugs because they eliminate errors associated with sample preparation and variability between analyses, increasing the method's accuracy and precision. Moreover, such methods are highly sensitive and specific.

Gemcitabine hydrochloride was used as an IS since it is structurally similar to the test substance, and the peaks obtained in the chromatogram were symmetric and had good resolution.

The chromatogram also showed no pronounced peaks of other compounds except the peak of lapatinib. It indicates that the excipients contained in the tablet did not affect the analysis results, confirming the method's specificity.

The retention time (RT) of lapatinib and gemcitabine hydrochloride were $4.25 \pm 0.05 \mathrm{~min}$ and $6.10 \pm 0.05 \mathrm{~min}$, respectively. The limit of detection (LOD) and limit of quantification (LOQ) of lapatinib were 26.5 and $88.4 \mu \mathrm{g} / \mathrm{l}$, respectively.

A simple and sensitive method of RP-HPLC-UV was developed to determine lapatinib together with related impurities in the bulk pharmaceuticals and finished tablets [27]. This method has also been validated for routine use in quality control laboratories.

In similar studies [26, 28-30], describing the determination of related impurities of lapatinib by HPLC, the resulting peak shapes of impurities were broad, and there was no clear separation between them. Since impurities can significantly affect the quality, safety, and efficacy of a drug, it is necessary to control its content.
The method described in the study by Ivaturi et al. made it possible to obtain a chromatogram with a symmetric peak shape and good resolution between them [27]. For this purpose, the products of forced degradation were introduced into the sample. As a result, it was found that all three known impurities (impurity 1, impurity 2, and impurity 3) were spectrally pure but at the same time had rather wide peak shapes. Analysis using the isocratic elution mode was also time-consuming.

To reduce the analysis time, its conditions were optimized. The elution mode was changed to the gradient. Mobile phase A was a ten mmol ammonium formate solution ( $\mathrm{pH} 4.5)$, and mobile phase B was acetonitrile. As a result, the total analysis time was reduced to $35 \mathrm{~min}$. The LOD and LOQ of lapatinib were 1 and $4 \mu \mathrm{g} / \mathrm{l}$, respectively [27].

The method of reverse-phase high-performance liquid chromatography using a diode array detector (RP-HPLC-DAD) was used to detect lapatinib in the bulk pharmaceuticals in the presence of its degradation products [28]. The RT of lapatinib was 4 min. The LOD and LOQ are 1 and $5 \mu \mathrm{g} / \mathrm{l}$, respectively.

Identification using a diode array is explained by the need to control the purity of the peaks. In addition, degradation products were analyzed by mass spectrometry to understand the degradation pathways better. The purpose of this study was not to identify degradation products of lapatinib but to study the purity of its peaks in the chromatogram.

This method allows to separate lapatinib and its degradation products; therefore, it can be used for analysis in forced degradation studies to determine the stability of the formulation. These tests showed that lapatinib is stable when exposed to high temperatures. Moreover, it is stable in a neutral environment and less stable in acidic and alkaline environments.

Some researchers point to the efficacy of the combined use of lapatinib and paclitaxel in patients with squamous cell carcinoma of the esophagus and HER2-positive breast cancer [31, 32]. Therefore, a reliable and fast RP-HPLC-DAD method was developed to determine these two drugs simultaneously [33]. This method was also used to assess the release profile of paclitaxel and lapatinib from polymeric micelle formulation.

Chromatographic conditions were similar to those in the study [31]. The differences were in the slower flow rate $(0.5 \mathrm{ml} / \mathrm{min})$, the volume of injected samples $(25 \mu \mathrm{l})$, and the intervals between injections of the sample (every $30 \mathrm{~min}$ ). The isocratic elution mode was also chosen for the analysis since it is simple and involves fewer variables that can potentially affect the method optimization process. The RT was 9 and 17 min for paclitaxel and lapatinib, respectively. The LOQ was $5 \mu \mathrm{g} / \mathrm{l}$ for both drugs.

Research by S. Biswal and S. Mondal aimed to develop and validate an ultra-high-performance liquid chromatography method specific to evaluating lapatinib in tablets in the presence of its degradation products [34].

The conditions for the analysis were optimized: the mobile phase was a mixture of $0.1 \%$ OPA buffer and acetonitrile $30: 70$ by volume). The flow rate was $0.25 \mathrm{ml} / \mathrm{min}$, and the volume of the injected sample was $5 \mu$ l. In addition, a matrix photodiode detector was chosen for detection.

The maximum absorption of lapatinib was observed at a wavelength of $309 \mathrm{~nm}$ (fig. 3). The total analysis time was 3 min. The LOD was $0.06 \mu \mathrm{g} / \mathrm{l}$ and the LOQ was $0.18 \mu \mathrm{g} / \mathrm{l}$. 


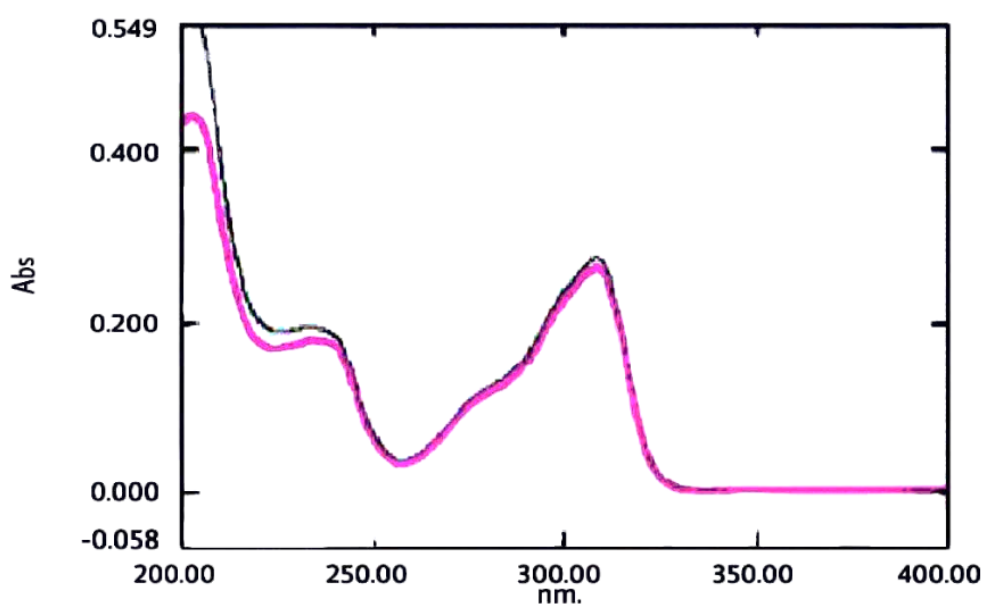

Fig. 3: Ultraviolet spectrum of lapatinib (with maximum absorption at a wavelength of $309 \mathrm{~nm}$ ) [31]

Based on the results of analysis of samples of forced degradation using the described method, it can be concluded that there is no intersection of their peaks with the major peak of lapatinib. This indicates that the developed method is specific for evaluating lapatinib in the presence of its degradation products. In addition, this method has excellent sensitivity, accuracy, and reproducibility.

In the study by Darwish et al. the conditions of fluorometric analysis of lapatinib in tablets and urine and in the presence of RH40 colliphore to enhance fluorescence were described for the first time [35]. The spectra (fig. 4) were recorded on a JASCO FP-8200 fluorescence spectrometer (JASCO Corporation, Japan) with a $150 \mathrm{~W}$ xenon lamp, quartz cuvettes $1 \mathrm{~cm}$ long, and a monochromator slit of $5.0 \mathrm{~nm}$. An 8-vial automatic dissolution tester (Abbott Corporation, US) was used to study drug release in vitro. The measurement was carried out at an analytical wavelength of $420 \mathrm{~nm}$ and an excitation wavelength of $292 \mathrm{~nm}$. The LOD was $27.31 \mu \mathrm{g} / \mathrm{l}$, and the method accuracy was $\geq 99.82 \%$.

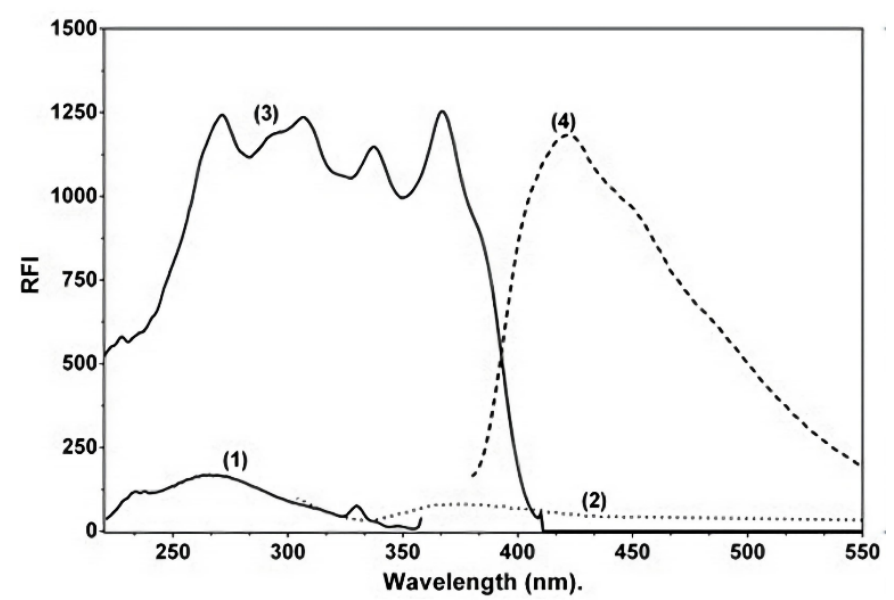

Fig. 4: Fluorescence spectra of lapatinib $(1000 \mathrm{ng} / \mathrm{ml})$ and a mixture of lapatinib-colliphor RH40 (2\%) [32], (1) and (2)-excitation and emission (respectively) of an aqueous solution of lapatinib in the absence of an RH colliphore; (3) and (4)-excitation and emission (respectively) of an aqueous solution of lapatinib containing RH colliphore

This method has been used successfully to determine lapatinib in tablets, perform dissolution tests and determine content uniformity. The scope of the technique was expanded to determine the drug in urine samples with an accuracy of $(99.82 \pm 3.45) \%$. The fluorimetric analysis is an environmentally friendly and efficient alternative to existing analytical methods for lapatinib determination.

\section{Pharmacokinetics studies}

When a drug is developed, it is important to define and understand its pharmacokinetics, including its absorption, distribution, metabolism, and excretion [36].

Most of the assays described in the literature have been developed to detect and quantify lapatinib after high doses of the drug in daily clinical practice [30, 37-39]. The purpose of Musijowski J. et al. study was to develop and validate a sensitive method of liquid chromatography in combination with a single quadrupole mass analyzer to determine lapatinib in human blood plasma [40]. This method is applicable for pharmacokinetics studies after a single oral dose of $0.25 \mathrm{~g}$ of lapatinib.

This method is characterized by high sensitivity: LOQ was $5 \mu \mathrm{g} / \mathrm{l}$. The total analysis time was $11 \mathrm{~min}$, the lapatinib RT was $3.5 \mathrm{~min}$.

For economic reasons, triple quadrupole mass spectrometry detectors are not as widely available as single quadrupole ones. Thus, this method expands the instrumental capabilities for the analysis of the drug.

\section{Pharmacokinetics preclinical studies}

Patients with metastatic breast cancer often suffer from pain at different stages of the disease. Paracetamol is one of the most common antipyretic and pain-relieving drugs. The most serious adverse reaction associated with paracetamol intake is the 
hepatotoxic effect of one of its metabolites, $\mathrm{N}$-acetyl-p-benzoquinone imine (NAPQI) [41]. Hepatotoxicity can be observed with insufficient amounts of glutathione [42]. Paracetamol and lapatinib will likely be used at the same time. Therefore, possible interactions between drugs can affect their pharmacokinetics. Consequently, it is important to know the potential effect of lapatinib on paracetamol metabolism in vivo.

Karbownik A. et al. study aimed to explore the effect of lapatinib oral administration on the pharmacokinetics of paracetamol, its glucuronidation, and sulfation in rats [43]. In addition, they analyzed the changes of lapatinib pharmacokinetics parameters after concomitant administration with paracetamol.

The study consisted of two parts. First, the concentrations of paracetamol, its glucuronide, and sulfate were determined using HPLC coupled with an ultraviolet detector (HPLC-UV) method. Second, quantitative determination of lapatinib in blood plasma samples was performed by HPLC in combination with a three-quadrupole mass spectrometric detector (HPLC-MS/MS). The LOQ was $0.25 \mu \mathrm{g} / \mathrm{l}$.

Lapatinib is a substrate and inhibitor of P-glycoprotein (Pgp). Inhibition of Pgp may increase the concentration of drugs that are its substrates [44]. Therefore, the risk of adverse reactions increases significantly when using lapatinib in combination with cytochrome P450 3A4 (CYP3A4) inhibitors such as clarithromycin, a widely used macrolide antibiotic.

Karbownik A. et al. investigated the effect of clarithromycin on the pharmacokinetics of lapatinib in rats [45]. For this, drugs were sequentially administered to rats: $0.025 \mathrm{~g} / \mathrm{kg}$ clarithromycin, then $0.100 \mathrm{~g} / \mathrm{kg}$ lapatinib.
Quantitative determination of lapatinib in blood plasma samples was carried out by HPLC-MS/MS. The method also assumed the use of erlotinib as an IS since it is a structural analogue of lapatinib. The selected IS ensured the high accuracy and precision of the method. The LOQ was $0.25 \mu \mathrm{g} / \mathrm{l}$.

In 1997, a group of scientists demonstrated the possibility of molecular imaging of peptides on biological tissue sections using matrix laser desorption ionization in combination with mass spectrometry (MALDI-MSI) [46]. This method has many advantages that make it most suitable for mapping pharmaceuticals in tissues: it is a high-sensitivity method capable of detecting small amounts of the analyte [47]. In addition, detection by mass spectrometry allows simultaneous imaging of several species and distinguishing between the distribution of the parent drug and its metabolites. An additional advantage is that mass spectroscopy does not require the use of radiolabeled standards, so such studies are most cost-effective in the early stages of the drug development process.

Barry J. A. et al. detected lapatinib and several metabolites in liver tissue by mass spectrometric imaging using infrared array laser desorption with electrospray ionization (IR-MALDESI). The method was combined with high-resolution mass spectrometers and ion cyclotron Fourier Transform Resonance (FT-ICR). IR-MALDESI is the first method with atmospheric pressure ionization. Although the MALDESI process was first described for ultraviolet desorption, it is independent of the laser wavelength. Hence any laser wavelength can be used, provided the appropriate absorbing matrix (endogenous or exogenous) is selected [48].

Summarized information on the described methods of lapatinib analysis is given in table 2 .

Table 2: Methods of lapatinib analysis

\begin{tabular}{|c|c|c|c|c|}
\hline Analysis method & Analyzed compound & Analysis object & Purpose of the study & Reference \\
\hline RP-HPLC-UV & Lapatinib & Tablets & Standardization, quality control & {$[26]$} \\
\hline RP-HPLC-UV & $\begin{array}{l}\text { Lapatinib in the presence of degradation } \\
\text { products }\end{array}$ & Tablets & Standardization, quality control & [27] \\
\hline RP-HPLC-DAD & Lapatinib together with paclitaxel & Polymeric micelles & $\begin{array}{l}\text { Standardization, establishment of release } \\
\text { profiles from a new dosage form }\end{array}$ & {$[28]$} \\
\hline RP-HPLC-DAD & $\begin{array}{l}\text { Lapatinib in the presence of degradation } \\
\text { products }\end{array}$ & Tablets & Standardization, quality control & [33] \\
\hline UHPLC & Lapatinib & Tablets & Standardization & [34] \\
\hline Fluorimetry & Lapatinib & Tablets, urine & $\begin{array}{l}\text { Standardization, dissolution test, content } \\
\text { uniformity }\end{array}$ & [35] \\
\hline HPLC-MS & Lapatinib (in low concentrations) & Blood plasma & Pharmacokinetics studies & [40] \\
\hline HPLC-MS/MS & Lapatinib in the presence of paracetamol & Blood plasma & Pharmacokinetics preclinical studies & [43] \\
\hline HPLC-MS/MS & Lapatinib together with clarithromycin & Blood plasma & Pharmacokinetics preclinical studies & [45] \\
\hline IR-MALDESI & Lapatinib & Liver tissue & Pharmacokinetics preclinical studies & [48] \\
\hline
\end{tabular}

HPLC is one of the most widely used methods for the analysis of pharmaceuticals [49]. Table 3 shows the main characteristics of the conditions for the chromatographic determination of lapatinib.

Table 3: Characterization of conditions for chromatographic determination of lapatinib

\begin{tabular}{|c|c|c|c|c|c|c|}
\hline Analysis method & IS & Elution mode & RT, min & LOD, $\mu \mathrm{g} / \mathrm{l}$ & LOQ, $\mu \mathrm{g} / \mathrm{l}$ & Reference \\
\hline RP-HPLC-UV & Gemcitabine & Isocratic & $4.25 \pm 0.05$ & 26.5 & 88.4 & {$[26]$} \\
\hline RP-HPLC-UV & None & Gradient & 15.21 & 1 & 4 & [27] \\
\hline RP-HPLC-DAD & None & Isocratic & 4 & 1 & 5 & [28] \\
\hline RP-HPLC-DAD & None & Isocratic & 17 & 1 & 5 & [33] \\
\hline UHPLC & None & Isocratic & 0.516 & 0.06 & 0.18 & [34] \\
\hline HPLC-MS & Isotope labeled lapatinib & Isocratic & 3.5 & - & 5 & [40] \\
\hline HPLC-MS/MS & Erlotinib & Gradient & - & - & 0.25 & [43] \\
\hline HPLC-MS/MS & Erlotinib & Gradient & - & - & 0.25 & [45] \\
\hline
\end{tabular}

\section{CONCLUSION}

From the described methods, it is preferable to use RP-HPLC, using an IS for the quantitative determination of lapatinib in dosage forms.
Several new methods for the quantitative determination of lapatinib using HPLC in combination with various types of detectors in biological fluids have been described. However, these methods are not applicable for determining the drug directly in dosage forms and require further development and validation. 


\section{FUNDING}

Nil

\section{AUTHORS CONTRIBUTIONS}

All the authors have contributed equally.

\section{CONFLICT OF INTERESTS}

Declared none

\section{REFERENCES}

1. Bray F, Ferlay J, Soerjomataram I, Siegel RL, Torre LA, Jemal A. Global cancer statistics 2018: GLOBOCAN estimates of incidence and mortality worldwide for 36 cancers in 185 countries. CA Cancer J Clin. 2018 Nov;68(6):394-424. doi: 10.3322/caac.21492. Erratum: CA Cancer J Clin. 2020 Jul;70(4):313, PMID 30207593.

2. Xuhong JC, Qi XW, Zhang Y, Jiang J. Mechanism, safety and efficacy of three tyrosine kinase inhibitors lapatinib, neratinib and pyrotinib in HER2-positive breast cancer. Am J Cancer Res. 2019 Oct 1;9(10):2103-19. PMID 31720077, PMCID PMC6834479.

3. Dange VN, Shid SJ, Magdum CS, Mohite SK. A review on breast cancer: an overview. Asian J Pharm Res. 2017;7(1):3. doi: 10.5958/2231-5691.2017.00008.9.

4. Oh DY, Bang YJ. HER2-targeted therapies - a role beyond breast cancer. Nat Rev Clin Oncol. 2020 Jan;17(1):33-48. doi: 10.1038/s41571-019-0268-3. PMID 31548601.

5. O'Sullivan CC, Davarpanah NN, Abraham J, Bates SE. Current challenges in the management of breast cancer brain metastases. Semin Oncol. 2017 Apr;44(2):85-100. doi: 10.1053/j.seminoncol.2017.06.006. PMID 28923217.

6. Holla SN, Nayak V, Laxminarayan Bairy K, Tripathy A, Shreedhar Holla N. Her-2 gene, receptors and drug target: a systematic review. Int J Pharm Pharm Sci. 2016 Jan;8(4):6.

7. European Medicines Agency. Assessment report for Tyverb; 2008. p. 58.

8. Gril B, Palmieri D, Bronder JL, Herring JM, Vega Valle E, Feigenbaum L, Liewehr DJ, Steinberg SM, Merino MJ, Rubin SD, Steeg PS. Effect of lapatinib on the outgrowth of metastatic breast cancer cells to the brain. J Natl Cancer Inst. 2008 Aug 6;100(15):1092-103. doi: 10.1093/jnci/djn216. PMID 18664652, PMCID PMC2575427.

9. Konecny GE, Pegram MD, Venkatesan N, Finn R, Yang G, Rahmeh M, Untch M, Rusnak DW, Spehar G, Mullin RJ, Keith BR, Gilmer TM, Berger M, Podratz KC, Slamon DJ. Activity of the dual kinase inhibitor lapatinib (GW572016) against HER-2overexpressing and trastuzumab-treated breast cancer cells. Cancer Res. 2006 Feb 1;66(3):1630-9. doi: 10.1158/00085472.CAN-05-1182. PMID 16452222.

10. Shrivastava R, Trivedi S, Singh PK, Asif M, Chourasia MK, Khanna A, Bhadauria S. Design and development of pegylated liposomal formulation of HER2 blocker Lapatinib for enhanced anticancer activity and diminished cardiotoxicity. Biochem Biophys Res Commun. 2018 Sep 5;503(2):677-83. doi: 10.1016/j.bbrc.2018.06.060. PMID 29908185.

11. Yang Z, Shao D, Zhou G. Dissolution behavior and thermodynamic properties of lapatinib ditosylate in pure and mixed organic solvents from T = (283.15-323.15) K. Fluid Phase Equilib. 2019 May;486:91-7. doi: 10.1016/j.fluid.2019.01.005.

12. Open database: the Human metabolome Database (HMDB); c2012. Available from: https://hmdb.ca/metabolites/HMDB0015388. [Last accessed on 10 Nov 2020].

13. Morikawa A, Peereboom DM, Thorsheim HR, Samala R, Balyan R, Murphy CG, Lockman PR, Simmons A, Weil RJ, Tabar V, Steeg PS, Smith QR, Seidman AD. Capecitabine and lapatinib uptake in surgically resected brain metastases from metastatic breast cancer patients: a prospective study. Neurooncol. 2015 Feb;17(2):289-95. doi: 10.1093/neuonc/nou141. Erratum in: Oncol N. PMID: 25015089; PMC ID: PMC4288517. 2015 Oct;17(10):1423.

14. Toth G, Janoska A, Volgyi G, Szabo Z, Orgovan G, Mirzahosseini A, Noszal B. Physicochemical characterization and cyclodextrin complexation of the anticancer drug lapatinib. J Chem. 2017 Mar;2017:1-9. doi: 10.1155/2017/4537632.
15. Stuurman FE, Nuijen B, Beijnen JH, Schellens JH. Oral anticancer drugs: mechanisms of low bioavailability and strategies for improvement. Clin Pharmacokinet. 2013 Jun;52(6):399-414. doi: 10.1007/s40262-013-0040-2, PMID 23420518.

16. Wan X, Zheng X, Pang X, Zhang Z, Zhang Q. Incorporation of lapatinib into human serum albumin nanoparticles with enhanced anti-tumor effects in HER2-positive breast cancer Colloids Surf B Biointerfaces. 2015 Dec 1;136:817-27. doi: 10.1016/j.colsurfb.2015.10.018. PMID 26539808.

17. Bouchet S, Chauzit E, Ducint D, Castaing N, Canal-Raffin M, Moore N, Titier K, Molimard M. Simultaneous determination of nine tyrosine kinase inhibitors by 96-well solid-phase extraction and ultra-performance LC/MS-MS. Clin Chim Acta. 2011 May 12;412(11-12):1060-7. doi: 10.1016/j.cca.2011. 02.023. PMID 21345336.

18. Ni MW, Zhou J, Li H, Chen W, Mou HZ, Zheng ZG. Simultaneous determination of six tyrosine kinase inhibitors in human plasma using HPLC-Q-Orbitrap mass spectrometry. Bioanalysis. 2017 Jun;9(12):925-35. doi: 10.4155/bio-2017-0031. PMID 28617069.

19. Merienne C, Rousset M, Ducint D, Castaing N, Titier K, Molimard $\mathrm{M}$, Bouchet S. High throughput routine determination of 17 tyrosine kinase inhibitors by LC-MS/MS. J Pharm Biomed Anal. 2018 Feb 20;150:112-20. doi: 10.1016/j.jpba.2017.11.060. PMID 29220734.

20. Zardavas D, Fouad TM, Piccart M. Optimal adjuvant treatment for patients with HER2-positive breast cancer in 2015. Breast. 2015 Nov;24Suppl 2:S143-8. doi: 10.1016/ j.breast.2015.07.034, PMID 26255196.

21. Inoue K, Kuroi K, Shimizu S, Rai Y, Aogi K, Masuda N, Nakayama T, Iwata H, Nishimura Y, Armour A, Sasaki Y. Safety, pharmacokinetics and efficacy findings in an open-label, single-arm study of weekly paclitaxel plus lapatinib as first-line therapy for Japanese women with HER2-positive metastatic breast cancer. Int J Clin Oncol. 2015 Dec;20(6):1102-9. doi: 10.1007/s10147-015-0832-5. PMID 25967286, PMCID PMC4666271.

22. Schrader C, Boehm A, Reiche A, Dietz A, Mozet C, Wichmann G. Combined effects of lapatinib and cisplatin on colony formation of head and neck squamous cell carcinoma. Anticancer Res. 2012 Aug;32(8):3191-9. PMID 22843892.

23. McDermott M, Eustace AJ, Busschots S, Breen L, Crown J, Clynes M, O'Donovan N, Stordal B. In vitro development of chemotherapy and targeted therapy drug-resistant cancer cell lines: a practical guide with case studies. Front Oncol. 2014 Mar 6;4:40. doi: 10.3389/fonc.2014.00040, PMID 24639951, PMCID PMC3944788.

24. Umehara H, Maekawa Y, Koizumi F, Shimizu M, Ota T, Fouad TM, Willey J, Kaito H, Shiraishi N, Nakashima D, Akinaga S, Ueno NT. Preclinical and phase I clinical studies of KW-2450, a dual IGF-1R/IR tyrosine kinase inhibitor, in combination with lapatinib and letrozole. Ther Adv Med Oncol. 2018 Jul 30;10:1758835918786858. doi: 10.1177/1758835918786858, PMID 30083253, PMCID PMC6066809.

25. Cizkova M, Bouchalova K, Friedecky D, Polynkova A, Janostakova A, Radova L, Cwiertka K, Trojanec R, Zezulova M, Zlevorova M, Hajduch M, Melichar B. High lapatinib plasma levels in breast cancer patients: risk or benefit? Tumori. 2012 Jan-Feb;98(1):1625. doi: 10.1700/1053.11516, PMID 22495718.

26. Kumar KK, Nagoji KE, Nadh RV. A validated RP-HPLC method for the estimation of lapatinib in tablet dosage form using gemcitabine hydrochloride as an internal standard. Indian J Pharm Sci. 2012 Nov;74(6):580-3. doi: 10.4103/0250474X.110621, PMID 23798787, PMCID PMC3687931.

27. Ivaturi R, Sastry MT, Satyaveni S. Development and validation of stability-indicating HPLC method for the determination of lapatinib impurities in bulk and finished formulations. Int J Pharm Sci Res. 2017 Jul;8:3081-91. doi: 10.13040/IJPSR.09758232.8(7).3081-91.

28. Saadat E, Dehghan Kelishady P, Ravar F, Kobarfard F, Dorkoosh FA. Development and validation of rapid stability-indicating RP-HPLC-DAD method for the quantification of lapatinib and mass spectrometry analysis of degraded products. J Chromatogr Sci. 2015 Jul;53(6):932-9. doi: 10.1093/chromsci/ bmu150. PMID 25491314. 
29. Götze L, Hegele A, Metzelder SK, Renz H, Nockher WA. Development and clinical application of a LC-MS/MS method for simultaneous determination of various tyrosine kinase inhibitors in human plasma. Clin Chim Acta. 2012 Jan 18;413(1-2):143-9. doi: 10.1016/j.cca.2011.09.012. PMID 21945732.

30. Couchman L, Birch M, Ireland R, Corrigan A, Wickramasinghe S, Josephs D, Spicer J, Flanagan RJ. An automated method for the measurement of a range of tyrosine kinase inhibitors in human plasma or serum using turbulent flow liquid chromatographytandem mass spectrometry. Anal Bioanal Chem. 2012 Jun;403(6):1685-95. doi: 10.1007/s00216-012-5970-2. PMID 22526649.

31. Guo XF, Li SS, Zhu XF, Dou QH, Liu D. Lapatinib in combination with paclitaxel plays synergistic antitumor effects on esophageal squamous cancer. Cancer Chemother Pharmacol. 2018 Sep;82(3):383-94. doi: 10.1007/s00280-018-3627-3. PMID 29909520.

32. Patel TA, Ensor JE, Creamer SL, Boone T, Rodriguez AA, Niravath PA, Darcourt JG, Meisel JL, Li X, Zhao J, Kuhn JG, Rosato RR, Qian W, Belcheva A, Schwartz MR, Kaklamani VG, Chang JC. A randomized, controlled phase II trial of neoadjuvant ado-trastuzumab emtansine, lapatinib, and nabpaclitaxel versus trastuzumab, pertuzumab, and paclitaxel in HER2-positive breast cancer (TEAL study). Breast Cancer Res. 2019 Sep 2;21(1):100. doi: 10.1186/s13058-019-1186-0, PMID 31477168, PMCID PMC6720931.

33. Saadat E, Ravar F, Dehghankelishadi P, Dorkoosh FA. Development and validation of a rapid RP-HPLC-DAD analysis method for the simultaneous quantitation of paclitaxel and lapatinib in a polymeric micelle formulation. Sci Pharm. 2016 Apr-Jun;84(2):333-45. doi: 10.3797/scipharm.1507-03. PMID 27222608 , PMCID PMC4871185.

34. Biswal S, Mondal S. Analytical method validation report for assay of lapatinib by UPLC. Pharm Methods. 2019 Apr;10(1):09-14. doi: 10.5530/phm.2019.1.2.

35. Darwish HW, Bakheit AH, Al-Shakliah NS, Rahman AFMM, Darwish IA. Experimental and computational evaluation of kolliphor RH 40 as a new fluorescence enhancer in the development of a micellarbased spectrofluorimetric method for determination of lapatinib in tablets and urine. PLOS ONE. 2020 Dec 3;15(12):e0239918. doi: 10.1371/journal.pone.0239918. PMID 33270656, PMCID PMC7714224.

36. Caprioli RM, Farmer TB, Gile J. Molecular imaging of biological samples: localization of peptides and protein S using MALDITOF MS. Anal Chem. 1997 Dec 1;69(23):4751-60. doi: 10.1021/ac970888i, PMID 9406525.

37. Andriamanana I, Gana I, Duretz B, Hulin A. Simultaneous analysis of anticancer agents bortezomib, imatinib, nilotinib, dasatinib, erlotinib, lapatinib, sorafenib, sunitinib and vandetanib in human plasma using LC/MS/MS. J Chromatogr B Analyt Technol Biomed Life Sci. 2013 May 1;926:83-91. doi: 10.1016/j.jchromb.2013.01.037. PMID 23562906.

38. Lankheet NAG, Hillebrand MJX, Rosing H, Schellens JHM, Beijnen JH, Huitema ADR. Method development and validation for the quantification of dasatinib, erlotinib, gefitinib, imatinib, lapatinib, nilotinib, sorafenib and sunitinib in human plasma by liquid chromatography coupled with tandem mass spectrometry. Biomed Chromatogr. 2013 Apr;27(4):466-76. doi: 10.1002/bmc.2814. PMID 22987603.

39. Micova K, Friedecky D, Faber E, Adam T. Isotope dilution direct injection mass spectrometry method for determination of four tyrosine kinase inhibitors in human plasma. Talanta. 2012 May 15;93:307-13. doi: 10.1016/j.talanta.2012.02.038, PMID 22483915.

40. Musijowski J, Filist M, Rudzki PJ. Sensitive single quadrupole LC/MS method for determination of lapatinib in human plasma. Acta Pol Pharm. 2014 Nov-Dec;71(6):1029-36. PMID 25745775.

41. Ganetsky M, Böhlke M, Pereira L, Williams D, LeDuc B, Guatam S, Salhanick SD. Effect of excipients on acetaminophen metabolism and its implications for prevention of liver injury. J Clin Pharmacol. 2013 Apr;53(4):413-20. doi: 10.1002/jcph.24. PMID 23436315, PMCID PMC4383763.

42. Lancaster EM, Hiatt JR, Zarrinpar A. Acetaminophen hepatotoxicity: an updated review. Arch Toxicol. 2015 Feb;89(2):193-9. doi: 10.1007/s00204-014-1432-2. PMID 25537186.

43. Karbownik A, Szałek E, Sobanska K, Grabowski T, Klupczynska A, Plewa S, Wolc A, Magiera M, Porażka J, Kokot ZJ, Grzeskowiak E. The concomitant use of lapatinib and paracetamol- the risk of interaction. Invest New Drugs. 2018 Oct;36(5):819-27. doi: 10.1007/s10637-018-0573-1. PMID 29464465 , PMCID PMC6153549.

44. Polli JW, Humphreys JE, Harmon KA, Castellino S, O'Mara MJ, Olson KL, John-Williams LSt, Koch KM, Serabjit-Singh CJ. The role of efflux and uptake transporters in [N-\{3-chloro-4-[(3fluorobenzyl)oxy]phenyl $\}-6-[5-(\{[2-$

(methylsulfonyl)ethyl]amino\}methyl)-2-furyl]-4quinazolinamine (GW572016, lapatinib) disposition and drug interactions. Drug Metab Dispos. 2008 Apr;36(4):695-701. doi: 10.1124/dmd.107.018374. PMID 18216274.

45. Karbownik A, Porażka J, Łuczak A, Teżyk A, Grabowski T, Wolc A, Grześkowiak E, Szałek E. Pharmacokinetic interaction after oral coadministration of clarithromycin and the tyrosine kinase inhibitor lapatinib in rats. Acta Poloniae Pharmaceutica- Drug Research. 2019 Aug;76(4):645-51. doi: $10.32383 / \mathrm{appdr} / 104370$.

46. Langer 0 , Müller $M$. Methods to assess tissue-specific distribution and metabolism of drugs. Curr Drug Metab. 2004 Dec;5(6):463-81. doi: 10.2174/1389200043335379, PMID 15578942.

47. Jespersen S, Niessen WMA, Tjaden UR, van der Greef J, Litborn E, Lindberg U, Roeraade J, Hillenkamp F. Attomole detection of proteins by matrix-assisted laser desorption/ionization mass spectrometry with the use of picolitre vials. Rapid Commun Mass Spectrom. 1994;8:581-4.

48. Barry JA, Groseclose MR, Robichaud G, Castellino S, Muddiman DC. Assessing drug and metabolite detection in liver tissue by UV-MALDI and IR-MALDESI mass spectrometry imaging coupled to FT-ICR MS. Int J Mass Spectrom. 2015 Feb 1;377:448-55. doi: 10.1016/j.ijms.2014.05.012. PMID 26056514, PMCID PMC4456684.

49. Khan H. Analytical method development in pharmaceutical research: steps involved in HPLC method development. Asian J Pharm Res. 2017;7(3):203-7. doi: 10.5958/2231-5691. 2017. 00031.4 . 